\title{
Glycerol from Biodiesel Production: The New Corn for Dairy Cattle Shawn S Donkin
}

\author{
${ }^{1}$ Purdue University, West Lafayette, IN 47907
}

\begin{abstract}
Glycerol, also known as glycerin, is a colorless, odorless, hygroscopic, and sweet-tasting viscous liquid. It is a sugar alcohol with high solubility index in water and has a wide range of applications in the food, pharmaceutical, and cosmetic industries. The use of glycerol in diets for dairy cattle is not novel; however, this interest has been renewed due to the increased availability and favorable pricing of glycerol as a consequence of recent growth in the biofuels industry. Experimental evidence supports the use of glycerol as a transition cow therapy but feeding rates are low, ranging from 5 to $8 \%$ of the diet DM. There is a paucity of research that examines the use of glycerol as a macro-ingredient in rations for lactating dairy cows. Most reports indicate a lack of effect of addition of glycerol to the diet when it replaces corn or corn starch. Recent feeding experiments with lactating dairy cows indicate replacing corn with glycerol to a level of $15 \%$ of the ration DM does not adversely effect milk production or composition. Milk production was 37.0, 36.9, 37.3, $36.4 \pm 0.6 \mathrm{~kg} / \mathrm{d}$ and feed intake was 24.0, 24.5, 24.6, $24.1 \pm 0.5 \mathrm{~kg} / \mathrm{d}$ for 0, 5, 10 and 15\% glycerol treatments respectively and did not differ $(\mathrm{P}>0.05)$ except for a modest reduction in feed intake during the first 7 days for the 15\% glycerol treatment. Glycerol fed to dairy cattle is fermented to volatile fatty acids in the rumen and early reports indicated that glycerol is almost entirely fermented to propionate. In vitro data indicates glycerol fermentation increases the production of propionate and butyrate at the expense of acetate. Rumen microbes appear to adapt to glycerol feeding and consequently, cows fed glycerol also require an adaptation period to glycerol inclusion. Debate exists regarding the fate of glycerol in the rumen and although most reports suggest that glycerol is largely fermented in the rumen, the extent of rumen digestion may depend on level of inclusion in the diet. Data are lacking regarding the rates of rumen fermentation of glycerol at intake levels for high producing dairy cattle. Current data indicates that glycerol can be included in diets fed to dairy cattle at macro ingredient levels; however, additional information is needed to permit a full appreciation of the feeding value of glycerol and the resulting impact on cow health and productivity.
\end{abstract}

\section{Introduction}

Glycerol is a colorless, odorless, hygroscopic, and sweet-tasting viscous liquid. Synonous names for glycerol include glycerin, glycerine, propane-1,2,3-triol, 1,2,3-propanetriol, 1,2,3-trihydroxypropane, glyceritol, and glycyl alcohol. By definition glycerol it is a sugar alcohol. Because of its humectant properties, energy content, and high solubility index in water glycerol is widely utilized in the food, pharmaceutical, and cosmetic industries. With expansion of the biofuels industry including further processing of soybean oil to produce biodiesel fuel there is a potential for increased availability of unrefined glycerol, a byproduct, as a valuable energy source for livestock. Although glycerol may be an alternative energy source for livestock there are unanswered question regarding the handling, inclusion rates, impact and level of contaminants, and feeding value relative to other energy sources. This review will explore some of the attributes and issues pertinent to glycerol as a feed for lactating dairy cows and highlight results from ongoing at Purdue University where the value of glycerol has examined as a replacement for corn grain.

\section{Glycerol from biodiesel production}

The term 'bio-diesel' is used to describe the primary endproduct of the methyl or sometimes ethyl esters of fatty acids that are produced from processing of lipid derived from a variety of plant sources. Every 50 liters of biodiesel that is produced generates about $4.5 \mathrm{~kg}$ of crude glycerol. According to the National Biodiesel Board the production of biodiesel in the U.S. over the next decade is expected to grow (http://www.biodiesel.org/). Current annual production is 1493 million liters and planned expansions in the biodiesel industry are expected to drive that capacity to more than 4.2 billion liters within the next 18 months, generating more than 350 million $\mathrm{kg}$ of glycerol 
annually. Corresponding price projections suggest glycerol could be priced competitively with grains as a source of energy for livestock. The value of glycerol in this regard may be further amplified with increasing diversion of corn and other grains to ethanol production.

\section{Glycerol production and quality concerns}

Most biodiesel is currently produced by a reaction that utilizes a base catalyzed transesterification of the oil. For soy diesel production, soybean oil is reacted with an equal weight of a short chain alcohol (usually methanol but sometimes ethanol) in the presence of a catalyst (sodium hydroxide; caustic soda or potassium hydroxide; potash) to yield biodiesel and crude glycerol. This process requires low temperature and pressure, yields high conversion (98\%) with minimal side reactions and reaction time and results in direct conversion of soybean oil to biodiesel with no intermediate compounds. The biodiesel is separated from the glycerol by gravity separation or by centrifugation. Because most commercial biodiesel production utilizes a 6 to 1 molar ratio of alcohol to oil, or excess alcohol to drive the reaction to completion, methanol can partition to the glycerol and biodiesel phases.

Alcohol is removed from biodiesel and glycerol phases by flash evaporation or distillation, to be recovered, and re-used. The resulting glycerol contains unused catalyst and soaps which are then neutralized by the addition of acid to produce crude glycerin containing $80-88 \%$ glycerol. Further purification of crude glycerin to $99 \%$ or higher purity is needed for use in the cosmetic and pharmaceutical industries. Impurities devalue crude glycerol high levels of residual catalyst, salts, and methanol may be problematic in using of glycerol as a livestock feed. Recent evaluation of crude glycerol from soy biodiesel production indicates a content of glycerol of $76.2 \%$ and as much as $7.98 \%$ fat, $0.05 \%$ protein, and $2.73 \%$ ash. The latter was composed of 11 ppm Ca, 6.8 ppm Mg, 53 ppm P, and $1.2 \% \mathrm{Na}$ (Thompson and He, 2006).

Glycerin is generally recognized as safe for use in animal feed (FDA, 21 C.F.R. 582.1320). Although food grade glycerol is safe in this regard concerns have been expressed relative to contaminant levels in crude glycerol from biodiesel production. Methanol levels are of particular concern and the methanol content of crude glycerol should be less than $0.5 \%$. A recent regulatory letter issued by FDA indicates that methanol levels higher than $150 \mathrm{ppm}$ could be considered unsafe for animal feed.

\section{Glycerol for transition cows at low inclusion levels}

The use of glycerol in the treatment of ketosis was reported as early as 1954 (Johnson et al., 1954) and evaluation of glycerol as well as propylene glycol as a ketosis treatment was further explored in the 1970's (Fisher et al., 1971, 1973). More recently the value of glycerol has been examined as a preventative aid for metabolic problems associated with transition cows. Goff and Horst (2001) used up to $3 \mathrm{~L}$ in ketosis treatment and prevention and DeFrain et al (2004) fed $0.86 \mathrm{~kg} / \mathrm{d}$ to transition dairy cattle. While these studies demonstrate the potential value of glycerol in treating ketosis there is a lack of data to examine the value of glycerol as a primary ration ingredient for posttransition dairy cattle. Feeding rates for transition cows range from 5 to $8 \%$ of the diet DM.

\section{Feeding studies using higher inclusion levels of glycerol}

Although there is supporting evidence for use of glycerol for transition cows there is little information that examines the use of glycerol as a macro-ingredient in rations for lactating dairy cows. Feeding studies have typically been lower from 150 to $472 \mathrm{~g} / \mathrm{d}$ (Fisher et al (1971, 1973; Kalili et al 1997). There are only a handful of studies with glycerol feeding rates that approach $5 \%$ or more of the ration on a dry matter (DM) basis.

Schröder and Südekum (1999) fed 10\% glycerol to dairy cattle, effectively replacing over one-half of the starch in the diet, without negatively affecting intake, ruminal digestibility, rumen microbial synthesis or total tract nutrient digestibility in steers. Feeding 3.6\% glycerol to mid-lactation dairy cows was without effect on intake, milk production, or gross milk composition but slightly altered the profile of fatty acids in milk and increased rumen propionate and butyrate at the expense 
of reduced acetate (Khalil et al., 1997). Feeding $0.86 \mathrm{~g}$ of glycerol to +21 days relative to calving $(5.4 \%$ of ration DM) did not have any effects on milk production or feed intake (DeFrain et al., 2004). Feeding $500 \mathrm{ml}$ of glycerol, or approximately $3.1 \%$ of dry matter, from 3 weeks prior to calving through to 70 days in milk caused an increase milk yield and milk protein content in milk (Bodarski et al., 2005). Taken together these experiments indicate that glycerol may be added to diets for lactating cows to a level of at least $10 \%$ of dry matter without deleterious effects and in some cases beneficial effects on milk production and composition.

\section{Energy value for glycerol}

Because glycerol has not been used as a macro ingredient the estimates of net energy of lactation $\left(\mathrm{NE}_{\mathrm{l}}\right)$ are not available for typical feeding scenarios. Schröder and Südekum (1999) reported estimates from 1.98 to $2.26 \mathrm{Mcal} / \mathrm{kg}$ with energy values decreasing for higher starch diets, and recently DeFrain (2004) reported 1.91 $\mathrm{Mcal} / \mathrm{kg}$ when feeding glycerol in early lactation. Part of the uncertainty for assigning an energy value for glycerol is due to the impact of the potential impact of the levels of glycerol that have been fed to ruminants and unknown interactions with other ration components. The energy value of glycerol is approximately equal to the energy contained in corn starch. However the experimental estimates for the energy value of glycerol when it replaced corn in the ration is reduced if the diet already has a high proportion of corn and a high starch content (55\% of ration DM) (Schröder and Südekum, 1999). The energy estimates for glycerol are greater when it is fed in a low starch ( $40 \%$ of ration dry matter). Therefore based on the typical starch levels in rations fed to dairy cattle an energy value for glycerol that is equal to the energy value of corn starch is an appropriate starting point until more information is available.

\section{Rumen metabolism of glycerol}

Glycerol is fermented to volatile fatty acids (VFA) in the rumen. Early reports of glycerol fermentation indicated that glycerol was almost entirely fermented to propionate (Johns et al., 1953; Garton et al., 1961). Other reports indicate an increase in acetic and propionic acids (Wright 1969) or increased propionic and butyric acids (Czerkawski and Breckenridge, 1972). In vitro glycerol fermentation using rumen fluid inoculum from cows adapted to glycerol feeding indicates increased production of propionate and butyrate at the expense of acetate (Remond et al., 1993). Studies using 14C labeled glycerol indicate that that most of the glycerol was found in propionate (Bergner et al., 1995). Rumen microbes adapt to glycerol feeding as the rates of glycerol disappearance from in rumen fluid are more rapid after 7 days of glycerol feeding to donor animals used as a source of rumen-fluid (Kijora et al., 1998). In studies where 15 to $25 \%$ glycerol was added most of the glycerol disappeared within 6 hours (Bergner et al., 1995).

The maximal rates of glycerol disappearance in the rumen determined using in vitro fermentors is 0.52 to 0.62 grams per hour (Remond et al., 1993). There is lack of agreement for in vivo disappearance from the rumen as microbial metabolism. Estimates from disappearance of a $200 \mathrm{~g}$ dose of glycerol indicate that more than $85 \%$ of glycerol in the rumen disappears within 2 hours in cattle acclimated to glycerol feeding (Kijora et al., 1998). Other data using a dose of $240 \mathrm{~g}$ of glycerol indicates rumen disappearance rates ranging between 1.2 to $2.4 \mathrm{~g}$ per hour (Remond et al., 1993). Likewise there have been reports suggests that a portion of the glycerol entering the rumen can be absorbed directly (Remond et al., 1993). The fate of any absorbed glycerol is metabolism in liver and requires glycerol kinase (Lin, 1977), and enzyme responsible for channeling glycerol into the triose phosphate step of glycolysis/gluconeogenesis. When glucose demands are high such as the case for lactating cows the fates of absorbed glycerol or propionate produced by rumen fermentation are likely to be identical.

\section{Feeding experiments with glycerol at Purdue University}

The objective of our feeding trial was to evaluate the value of glycerol as a replacement for corn grain in diets of lactating dairy cattle. For this experiment sixty lactating Holstein cows were housed in individual tie stalls at the Purdue Dairy Research and Education Center and adjusted to a basal diet for two week period. Cows were then assigned to diets containing $0,5,10$ or 
$15 \%$ glycerol as a percent of ration dry matter. For these experiments we used 99.5\% USP/FCC, Kosher grade glycerol in order to avoid any impact of potential contaminants found in crude glycerol. The basal $(0$ glycerol) ration was balanced to meet exceed or NRC requirements and contained corn silage, alfalfa haylage, hay, dry-rolled corn, vitamins, and minerals (Table 1). Corn was replaced by an equivalent amount of food grade glycerol and corn gluten feed. The addition of corn gluten adjusted for the protein removed with corn grain. Diets were offered once daily for ad libitum intake (5 to $10 \%$ weighbacks), feed refusals were measured daily and feed intake determined by difference. Cows will be milked twice daily and milk samples were obtained weekly at two consecutive milkings and analyzed for fat, protein, lactose, total solids, milk urea $\mathrm{N}$, and somatic cells.

Glycerol was well-tolerated by the cows and there were no differences in DM intake or milk production when the entire 8 week experimental period is considered (Table 2). Feed intake was reduced by inclusion of $15 \%$ glycerol during the first 7 days of the trial. Negative effects on intake were only evident during the first week of the test and differences were not detected for the subsequent 7 weeks. Recovery of intake within 7 days suggests that achieving a feeding rate of $15 \%$ glycerol might be best accomplished with a protocol that gradually introduces glycerol into the ration.

Milk production and milk composition were not altered in response to glycerol feeding with the exception of decreased milk urea nitrogen in response to glycerol. These changes were observed at all levels of glycerol feeding. Reduced MUN suggest improved use of dietary protein by rumen bacteria and reduced losses as ammonia. Cows fed the highest amount of glycerol gained the most weight during the 8 week feeding period. Cows fed 10 and $15 \%$ glycerol gained more weight than cows fed 5\% glycerol or the control diet. Weight gain for the control cows and $5 \%$ glycerol did not differ.

Rumen fluid samples were obtained by rumenocentesis at 4 hours after feeding from 4 cows in each treatment group and analyzed for VFA, lactate and rumen ammonia. There was no effect of glycerol on VFA concentrations or profile of acetate, propionate and butyrate. Total VFA was $119 \pm 5.9 \mathrm{mM}$ and 58.7, 23.3, and $17.8 \%$ acetate, propionate, and butyrate respectively. Rumen ammonia concentrations were 9.7 $\pm 2.7 \mathrm{mg} / \mathrm{dL}$ and were not affected by glycerol addition to the diet.

Estimates of $\mathrm{NE}_{\mathrm{l}}$ for the diets were calculated from intake, production data, and body weight (BW) changes. The energy content of each ration was calculated for each cow over the experimental period using total energy expenditure (milk, maintenance, BW gain) with $\mathrm{DM}$ intake. An estimate for $\mathrm{NE}_{\mathrm{l}}(\mathrm{Mcal} / \mathrm{kg})$ for of each diet was determined from $\mathrm{NE}_{1}$ used (Mcal) divided by DM consumed for the corresponding interval. Estimated energy values for the diets were $1.54,1.54,1.56$ and $1.58 \pm 0.04 \mathrm{Mcal} / \mathrm{kg}$ and were not different $(\mathrm{P}=0.90)$. The lack of differences in this regard suggests that glycerol can be substituted for corn without adjustments for the energy content. However the feed energy value of crude glycerol is likely to be less than that of pure glycerol and must be adjusted for the levels and energy content of the impurities. It should be noted that the energy values of the TMR, determined by chemical analysis are slightly higher than the estimates determined by difference of milk produced and BW change. These differences may reflect the effects of increasing intake and therefore passage rate to reduce the NE value of a ration.

\section{In vitro fermentation of glycerol or molasses}

The effects of pure glycerol on in vitro dry matter and fiber digestion of the nonglycerol components of the ration were assessed in vitro and compared with molasses as an alternative energy source. The fermenter diets were the same as those fed to the cows in the experiment described above. Diets were placed in bags inside Ankom Daisy Fermenters that contained either $0,5,10$, or $15 \%$ of either pure glycerol or cane molasses. Diets were fermented for 24 . The initial feed and fermentation residue was analyzed for organic matter and NDF content. The VFA profile of the incubation was determined.

Glycerol addition at 10 and $15 \%$ of the ration maintained in vitro DM digestion at during a $48 \mathrm{~h}$ incubation whereas molasses added above $5 \%$ reduced DM digestion by approximately $10 \%$. The digestion of NDF was unchanged by the addition of $15 \%$ glycerol by was decreased by approximately $30 \%$ by the 
addition of $15 \%$ molasses. The effects of glycerol on VFA profile of the incubation were moderate with few significant differences. Although there were no clear trends with inclusion level, glycerol increased the average propionate concentration. There were no significant differences between molasses and glycerol in total VFA production or profile of acetate, butyrate, or valerate.

The data suggest that glycerol improved DM digestion relative to molasses, largely because of lack of the negative effect of molasses on fiber digestion and the lack of effect of glycerol when added at $15 \%$ of the diet. The decrease in fiber digestion at the highest inclusion level of molasses may suggest the limitations of feeding high levels of sugar. The lack of negative effects of glycerol on fiber digestion suggests differences in glycerol and sugar fermentation. Glycerol appears to be a good dietary source of energy with a larger range for acceptable use compared with cane molasses.

Results from this study clearly indicate that glycerol is a valuable feed ingredient for lactating dairy cows. Glycerol can be included as a macro ingredient in diets for lactating dairy cows without any deleterious effects. In vitro data suggest glycerol fermentation to propionate at the expense of acetate and butyrate no negative impacts on digestibility of DM and NDF with

increasing glycerol in the diet. Therefore feeding glycerol in place of corn is an alternative strategy for formulating diets for lactating cows when corn is not priced favorability.

These data point to the feeding value of glycerol when fed in pure form however depending on the level and composition of impurities the feeding value of crude glycerol cannot be implied directly from these results.

\section{Summary}

Previously published research and recent work completed at Purdue University indicate the value of glycerol as a feed for lactating dairy cattle. Increased production of biodiesel and resulting glycerol when combined with an increased demand for corn in ethanol production may warrant use of glycerol as livestock feed. Although issues exist relative to the composition of crude glycerol there does not appear to be any detrimental impact of feeding glycerol up to at least $15 \%$ of the total ration dry matter. Caution should be used however when introducing glycerol to the diet as approximately 7 days is required to adapt the rumen to glycerol feeding.

Table 1. Diet composition.

\begin{tabular}{|c|c|c|c|c|}
\hline \multicolumn{5}{|c|}{ \% Glycerol } \\
\hline Ingredient, \% DM & 0 & 5 & 10 & 15 \\
\hline Corn Silage & & 31.94 & 31.94 & 31.94 \\
\hline Alfalfa Haylage & 10.00 & 10.00 & 10.00 & 9.98 \\
\hline Soy Hulls & & 7.66 & 7.66 & 7.66 \\
\hline 48\% Soybean Meal & 6.62 & 6.62 & 6.62 & 6.61 \\
\hline Roasted Soybeans & 5.40 & 5.40 & 5.40 & 5.39 \\
\hline Urea & & 0.30 & 0.30 & 0.30 \\
\hline Megalac R & & 0.98 & 0.98 & 0.98 \\
\hline Corn, Ground & & 20.00 & 14.20 & 8.40 \\
\hline Glycerol & - & 5.00 & 10.00 & 14.97 \\
\hline Corn Gluten Meal & - & 0.80 & 1.60 & 2.40 \\
\hline Mineral/Vitamin & 4.28 & 4.28 & 4.28 & 4.27 \\
\hline \multicolumn{5}{|c|}{ Chemical Analysis \% DM } \\
\hline $\mathrm{NDF}$ & 30.9 & 32.4 & 29.7 & 31.0 \\
\hline $\mathrm{NE}_{\mathrm{l}}, \mathrm{Mcal} / \mathrm{kg}$ & 1.69 & 1.67 & 1.69 & 1.69 \\
\hline $\mathrm{Ca}$ & 1.03 & 1.01 & 1.06 & 1.05 \\
\hline $\mathrm{P}$ & 0.41 & 0.39 & 0.41 & 0.41 \\
\hline $\mathrm{Mg}$ & 0.34 & 0.31 & 0.32 & 0.33 \\
\hline $\mathrm{K}$ & 1.88 & 1.85 & 1.88 & 1.88 \\
\hline $\mathrm{Na}$ & 0.25 & 0.24 & 0.28 & 0.27 \\
\hline
\end{tabular}


Table 2 - Effect of glycerol on feed intake, milk production, body weight change, and body condition score change.

\begin{tabular}{|c|c|c|c|c|c|c|}
\hline \multicolumn{7}{|c|}{ \% Glycerol } \\
\hline Item & 0 & 5 & 10 & 15 & SEM & $\mathrm{P}^{1}$ \\
\hline Milk production, $\mathrm{kg} / \mathrm{d}$ & 37.0 & 36.9 & 37.3 & 36.4 & 0.6 & 0.71 \\
\hline Feed intake, kg/d & 24.0 & 24.5 & 24.6 & 24.1 & 0.5 & 0.82 \\
\hline Efficiency, milk:feed & 0.71 & 0.69 & 0.69 & 0.70 & 0.02 & 0.85 \\
\hline Milk fat, kg/d & & 1.33 & 1.28 & 1.33 & 1.27 & 0.06 \\
\hline Milk protein, kg/d & 1.00 & 1.04 & 1.06 & 1.04 & 0.04 & 0.78 \\
\hline Milk lactose, kg/d & 1.66 & 1.69 & 1.76 & 1.67 & 0.08 & 0.84 \\
\hline SCC, 1000 cells/ml & 275 & 490 & 137 & 144 & 111 & 0.1 \\
\hline Milk urea N, mg/dl & $12.5^{\mathrm{a}}$ & $10.9^{\mathrm{b}}$ & $10.7^{\mathrm{b}}$ & $10.2^{\mathrm{b}}$ & 0.4 & $<0.05$ \\
\hline Milk fat, \% & 3.70 & 3.52 & 3.58 & 3.58 & 0.11 & 0.69 \\
\hline Milk protein, \% & 2.79 & 2.84 & 2.86 & 2.89 & 0.06 & 0.62 \\
\hline Milk lactose, \% & 4.64 & 4.62 & 4.70 & 4.66 & 0.07 & 0.89 \\
\hline Milk solids, \% & 12.05 & 11.89 & 12.03 & 12.04 & 0.19 & 0.91 \\
\hline BCS change & 0.1 & 0.1 & 0.1 & 0.1 & 0.1 & 0.91 \\
\hline
\end{tabular}

1. Probability that treatment means are equal.

a Means with different superscripts differ $(P<0.05)$.

Table 3 - Effect of glycerol or molasses on 24 hour in vitro DM and NDF digestion and VFA accumulation. Diets used were as listed in Table 1.

\begin{tabular}{|c|c|c|c|c|c|c|c|c|c|}
\hline \multicolumn{5}{|c|}{ Glycerol, \% } & \multicolumn{5}{|c|}{ Molasses, \% } \\
\hline Measure & 0 & 5 & 10 & 15 & 0 & 5 & 10 & 15 & SE \\
\hline DM digestion, \% & $62.7^{\mathrm{a}}$ & $59.8^{\mathrm{b}}$ & $61.3^{\mathrm{ab}}$ & $63.1^{\mathrm{a}}$ & $62.6^{a}$ & $62.3^{\mathrm{a}}$ & $56.9^{c}$ & $56.3^{c}$ & 0.4 \\
\hline NDF digestion, \% & $34.9^{\mathrm{ab}}$ & $30.8^{\mathrm{bc}}$ & $32.4^{\mathrm{abc}}$ & $35.2^{\mathrm{a}}$ & $36.1^{\mathrm{a}}$ & $35.9^{\mathrm{a}}$ & $29.9^{\text {cd }}$ & $26.2^{\mathrm{d}}$ & 0.8 \\
\hline Acetate, $\mathrm{mM}$ & 37.1 & 37.6 & 37.7 & 38.7 & 38.5 & 40.4 & 38.4 & 36.3 & 0.7 \\
\hline Propionate, mM & $18.1^{\mathrm{ab}}$ & $20.2^{\mathrm{ab}}$ & $20.1^{\mathrm{ab}}$ & $21.6^{\mathrm{a}}$ & $17.0^{\mathrm{b}}$ & $20.1^{\mathrm{ab}}$ & $18.4^{\mathrm{ab}}$ & $16.8^{\mathrm{b}}$ & 0.8 \\
\hline Butyrate, mM & 13.0 & 13.8 & 13.3 & 14.5 & 13.6 & 14.7 & 13.8 & 12.3 & 0.5 \\
\hline Valerate, mM & $5.7^{\mathrm{bc}}$ & $9.1^{\mathrm{a}}$ & $6.9^{\mathrm{abc}}$ & $8.2^{\mathrm{abc}}$ & $5.2^{\mathrm{c}}$ & $6.4^{\mathrm{abc}}$ & $8.5^{\mathrm{ab}}$ & $5.9^{\mathrm{bc}}$ & 0.6 \\
\hline
\end{tabular}

$\mathrm{a}, \mathrm{b}, \mathrm{c}, \mathrm{d}$. Means within the same row and section with different superscripts differ $\mathrm{P}<0.05$.

\section{References}

Bergner, H., C. Kijora , Z. Ceresnakova, and J. Szakacs. 1995 In vitro studies on glycerol transformation by rumen microorganisms. Arch Tierernahr. 48:245-256.

Bodarski, R., T. Wertelecki, F. Bommer, and S. Gosiewski. 2005. The Changes Of Metabolic Status And Lactation Performance In Dairy Cows Under Feeding TMR With Glycerin (Glycerol) Supplement At Periparturient Period. Electronic Journal of Polish Agricultural Universities, Animal Husbandry, 8:1-9.

Czerkawski, J. W., and G. Breckenridge. 1972. Fermentation of various glycolytic intermediates and other compounds by rumen micro-organisms, with particular reference to methane production. Br. J. Nutr. 27:131-146.

DeFrain J.M., A.R. Hippen, K.F. Kalscheur, and P.W. Jardon 2004. Feeding glycerol to transition dairy cows: effects on blood metabolites and lactation performance. J Dairy Sci. 87:4195-206.

Fisher, L. J., J. D. Erfle, and F. D. Sauer. 1971. Preliminary evaluation of the addition of glucogenic materials to the rations of lactating cows. Can. J. Anim. Sci. 51:721-727.

Fisher, L. J., J. D. Erfle, G. A. Lodge, and F. D. Sauer. 1973. Effects of propylene glycol or glycerol supplementation of the diet of dairy cows on feed intake, milk yield and composition, and incidence of ketosis. Can. J. Anim. Sci. 53:289-296.
Food and Drug Administration, Code of Federal Regulations, 21CFR582.1320, Title 21, Vol. 6, 2006. 21CFR582.1320.

Garton, G. A., A. K. Lough, and E. Vioque. 1961. Glyceride hydrolysis and glycerol fermentation by sheep rumen contents. J. Gen. Microbiol. 25:215-225

Goff, J. P., and R. L. Horst. 2001. Oral glycerol as an aid in the treatment of ketosis/fatty liver complex. J. Dairy Sci. 84(Suppl. 1):153. (Abstr.).

Johns, A. T. 1953. Fermentation of glycerol in the rumen of sheep. New Zealand J. Sci. Technol. 35:262-269.

Johnson, R. B. 1955. The treatment of ketosis with glycerol and propylene glycol. Cornell Vet. 44:6-21.

Khalili, H., T. Varvikko, V. Toivonen, K. Hissa, and M. Suvitie. 1997. The effects of added glycerol or unprotected free fatty acids or a combination of the two on silage intake, milk production, rumen fermentation and diet digestibility in cows given grass silage based diets. Ag. Food Sci. Finland. 6:349362.

Kijora C, H. Bergner, K.P. Gotz, J. Bartelt, J. Szakacs, and A. Sommer. 1998. Research note: investigation on the metabolism of glycerol in the rumen of bulls. Arch Tierernahr. 51:341-348.

Lin, E. C. C. 1977. Glycerol utilization and its regulation in mammals. Annu. Rev. Biochem. 46:765-795.

Rémond, B., E. Souday, and J. P. Jouany. 1993. In vitro and in vivo fermentation of glycerol by rumen microbes. Anim. Feed Sci. Technol. 41:121-132. 
Schröder, A., and K.-H. Südekum. 1999. Glycerol as a byproduct of biodiesel production in diets for ruminants. In New Horizons for an Old Crop. Proc. 10th Int. Rapeseed Congr., Canberra, Australia, September 26-29, Paper No. 241. N. Wratten and P. A. Salisbury, ed.
Thompson, J.C. and B. He. 2006. Characterization of crude glycerol from biodiesel production from multiple feedstocks. Applied Eng. Agri. 22(2): 261-265.

Wright D.E. 1969. Fermentation of glycerol by rumen microorganisms. N.Z. J. Agric. Res., 12:281-286. 